\title{
Evaluation of Effective Parameters in Disaster Risk Reduction Plans with Multi Criteria Decision Making Method: An Analysis on Selected Country Samples
}

\section{Şenay YILDIRIM}

Republic of turkey Ministry of Interior Disaster and emergency Management Presidency

Burcu ERTAŞ DENiZ ( $\nabla$ ertasburcu@gmail.com )

Republic of Turkey Ministry of Interior Disaster and emergency Management Presidency https://orcid.org/0000-0003-4666-7292

\section{Research Article}

Keywords: Disaster, Disaster Risk Reduction, Disaster Risk Reduction Plan, Analytical Hierarchy Process

Posted Date: December 14th, 2021

DOl: https://doi.org/10.21203/rs.3.rs-1064405/v1

License: (c) This work is licensed under a Creative Commons Attribution 4.0 International License.

Read Full License 


\title{
Evaluation of Effective Parameters in Disaster Risk Reduction Plans with Multi Criteria Decision Making Method: An Analysis on Selected Country Samples
}

\author{
Author(s): Şenay YILDIRIM a ${ }^{\text {, Burcu ERTAŞ DENİ }}{ }^{\text {b }}$ \\ ${ }^{a}$ Disaster and Emergency Management Authority, Ankara, Turkey \\ e-mail: senay.yildirim@gmail.com \\ Disaster and Emergency Management Authority, Ankara, Turkey \\ ${ }^{b}$ Correspond Author e-mail: ertasburcu@gmail.com
}

This study includes an approach that addresses how the criteria included in the national Risk Reduction Plans (DRR) of countries are measured quantitatively. Within the scope of the study, disaster management systems and DRR plans of countries with high disaster risk such as Japan, Turkey, Philippines and New Zealand were examined. The main criteria that make up the content of the DRR plans were determined. Risk Identification, Risk Reduction, Response and Recovery, Economic Disaster Risk Management, Disaster Preparedness, Governance and Compliance with Policies and Plans are selected as main criteria. 36 important components completing the main criteria were selected as sub-criteria. Then, all these criteria were weighted using multi-criteria decision-making process called the "Analytical Hierarchy Process". After the experts evaluated the existence of the main criteria and sub-criteria weighted with the AHP, country performance rankings were made for these four countries. As a result of the analysis, Japan was determined as the country with the best DRR plan and implementation, while our country ranked 2nd, New Zealand 3rd and Philippines 4th.

Key Words: Disaster, Disaster Risk Reduction, Disaster Risk Reduction Plan, Analytical Hierarchy Process 
Disaster management can be defined as the management of resources in line with these common goals with a multidisciplinary approach in order to plan, coordinate and implement the activities that should be done before, during and after the disaster in order to prevent disasters and reduce their negative effects (Kadığlu 2011).

Disaster management includes many levels. It is a comprehensive, multi-phase, multidisciplinary management style that starts from the individual and extends to the international level. Disaster management is the discipline of dealing with and avoiding risks, including usually four phases: Mitigation, Preparedness, Response and Recovery. The circular model for disaster management is generated to reduce the complexity of nonlinear nature of disaster events (Kelly 1998). Kimberly (2003), defines mitigation, preparation, response and recovery as four phases of disaster management. This model portrays response as the biggest and most visible phase of disaster management. In this study, the phase of disaster risk reduction is studied. Identification and analysis of hazards, risks and vulnerabilities, determination of resources and priorities to prevent or reduce risks, preparation and implementation of policies, strategies and action plans include key elements in disaster risk reduction (Taştan and Aydınoğlu 2015). DRR studies, which require a multidisciplinary approach, consist of activities that need to be planned and implemented before, during and after the disaster (Charlotte, John, and Rossetto 2007). DRR's activities include stages such as identification, analysis and evaluation of hazards and risks, establishment of early warning systems, spatial planning, DRR training, public information and awareness, development of disaster insurance, strengthening of critical infrastructures, institutional structuring, development of legal documents (IPCU 2014).

It is known that the direct economic cost of disasters is very high, and the impact of disasters on the country's economy becomes clearer when the direct economic costs of indirect and intangible effects are taken into account.

DRR activities to be carried out will reduce the economic losses that countries will experience after disasters. On average, every euro spent on DRR activities saves between four and seven euros on disaster response (ECHO 2017). Investments made without considering disaster risks cause socio-economic losses in the long run after the disaster. If countries are not prepared for disasters, the material and moral gains that countries have achieved for many years are destroyed in a short time due to disasters (Doroteo 2015)

Studies on DRR are carried out on a country basis in order to minimize the resources spent and the work done to compensate for the damage and economic losses caused by disasters, to increase the effectiveness of disaster management and to strengthen the capacity. In this context, one of the ways to cope with disasters is to make DRR plans according to each country's own dynamics. The DRR plan is defined as the plan of project work managed by risk management, which forms the basis for the implementation of the objectives and specific objectives of institutions and organizations for disaster risk reduction and the short, medium and long-term policies, strategies and actions to achieve them (AFAD 2016)

DRR plans help countries build their capacities by identifying the underlying causes of their vulnerabilities. The need to develop up-to-date action plans for existing and new DRR with the gains from past disasters also clearly demonstrates the importance of DRR plans. The scope and complexity of disasters, existing and new risks, and the evolving and changing world strengthen the dynamic nature of DRR plans.

Within the scope of the study, under the title of "Country Examples", the disaster management systems of Japan, Turkey, the Philippines and New Zealand, which are among the countries with high disaster risk, and their plans and documents related to DRR were examined. Then, criteria selections were made by examining the criteria in the DRR strategies 
and plans of the countries examined. The weights of the criteria were determined by using the opinions of the experts who worked on DRR through a questionnaire. In the conclusion part of the study, 4 countries were ranked by scoring with a holistic approach in line with the main criteria and sub-criteria determined by the plans and strategies of the selected countries for DRR.

\section{Country Samples}

\subsection{Japan}

Japan is a country located on islands in the western Pacific Ocean. Japan has been exposed to natural disasters (earthquake, volcanic activity, heavy rain, snowfalls and typhoons) from past to present due to its geographical location, topography, geological structure, climate and other factors, (Akyel 2007). Although the country covers only $0.25 \%$ of the planet's land area, the number of earthquakes and the distribution of active volcanoes are quite high due to its location in the "Pacific Ring of Fire". 110 active volcanoes in the region constitute about $10 \%$ of all active volcanoes in the world. Japan is one of the countries with the highest natural disaster risk in the world due to its susceptibility to earthquakes and tsunamis (Jimee, Meguro, and Dixit Mani 2019).

Disasters in Japan are generally categorized into two groups, natural disasters and accidenttype disasters. earthquake, tsunami, storm, flood, volcanic eruptions, heavy snowfall have bben Natural disasters; accident disasters include marine, aviation, railroad, road, nuclear, hazardous materials, large-scale fire and forest fire (Cabinet Office 2015). As a result of frequent earthquakes and typhoons in the 1940s and 1950s in Japan, the necessity of increasing the capacity of the society to respond to disasters and developing disaster risk management systems emerged. There have been changes in the systematic approaches adopted in disaster management, and the changes have also been reflected in the laws. The necessity of taking measures before disasters has been put into practice by law, and the country's disaster management system has been strengthened within the scope of the experiences gained after the disasters. Especially; the Ise-wan Typhoon that occurred in 1959 was a critical development in the country's disaster management approach, after which the Basic Law on Disaster Measures (1961), which had a comprehensive and strategic structure, was enacted. Roles and responsibilities related to disaster management within the scope of the law; clearly defined at the national, state and municipal as well as community level. The law has been constantly reviewed and updated since its first entry into force. Japan's disaster management system covers all stages of disaster management (prevention, mitigation, preparedness, response and recovery), and the public and private sector, whose duties and responsibilities at the national and local level are clearly defined, and the relevant stakeholders are based on cooperation and solidarity in taking measures against disasters. In Japan, the system of distribution of authorities and responsibilities is implemented, and there are many stakeholders at the national and local level in the administration of disaster management (Baba 2013).

A well-structured disaster management system has been developed in Japan. As part of the government reform in 2001, the State Ministry of Disaster Management was established in the Council of Ministers to integrate and coordinate disaster risk management policies. In the Cabinet Office (Fig. 1), the Director General of Disaster Management, who is responsible for ensuring wide-ranging cooperation between relevant government agencies, is responsible for planning basic disaster management policies and carrying out overall coordination as well as large-scale disaster response (Saya 2017). 
New Zealand is vulnerable to geological hazards such as earthquakes, landslides, volcanic activity, and tsunamis due to its location on the boundary of the Australian and Pacific tectonic plates. New Zealand is prone to a variety of hazards due to its geographical location in the South Pacific Ocean and its steep geography. While floods is the most common danger, earthquakes and tsunamis provide the most serious and deadly hazards to New Zealand. Volcanic eruptions, is from the other hand, have been extremely uncommon and minor since human settlement, but their impact have been considerable. (Britton and Clark 2000).

In addition to being a geologically active country, New Zealand is a coastal country affected by weather conditions from Antarctica, Australia and the tropics. Climate change; cause extreme weather events and sea level rise. Drought is one of the most common and costly hazards in the country as a result of the dry period that usually lasts for 3-4 months. Drought is an alarming danger for the country, as the country's electricity generation is largely supplied by rivers and lakes. These natural hazards occurring in the country often damage land and buildings, as well as important infrastructure systems of the country, including energy and communication networks, roads and water systems. In the last 10 years, natural hazard events in the country have cost the insurance industry $\$ 28,333$ billion (Saunders et al. 2020). In the previous 10 years, major disasters in New Zealand have demonstrated the severity of the destruction and the costs to the country. It seems to be noteworthy that the costs listed are usually simply direct costs. According to a new study, when the indirect and intangible costs of disasters are considered, one out of every three occurrences investigated costs more than twice as much as the overall cost stated (MCDEM 2019).

New Zealand's disaster management system is based on sound disaster management principles and one of international best practices. There are many strengths in the country's emergency management system. The system was established to deal with "all dangers and risks" (Ulutürk, 2006). As a result of a series of conferences, workshops, reports and researches that questioned the effectiveness of New Zealand's disaster management practice since the early 1990s, it was decided that a transformation from a rigid and reactive model to a coordinated proactive disaster management (Britton and Clark 2000).

In 1996, the principles, roles and responsibilities of all institutions in the sector were redefined, following the approval of a set of principles as the basis for a comprehensive disaster management framework. In 1997, it was decided to establish a new ministry called the Ministry of Civil Defense and Emergency Management (MCDEM), and it was established in 1999. In 2002, the Civil Defense Emergency Management (CDEM) Law was enacted, replacing the 1983 Civil Defense Law. By giving priority to the law, local interventions and administrations, most of the authority and responsibility has been transferred to local units .The primary purpose of the law is to promote the sustainable management of hazards and risks towards building a resilient and self-reliant society. The law transferred most of the authority and responsibility to local units by giving priority to local interventions and administrations (Ulutürk 2006).

Central to emergency management in New Zealand is an all-hazards, all risks, multi-agency, integrated and community-focused approach. The central decision-making body of executive government that addresses emergency management is the Cabinet Committee for Domestic and External Security Coordination (DES). The DES committee is chaired by the Prime minister, and includes those ministers responsible for departments that play essential roles in such situations. To support that process, the Officials' Committee for Domestic and External 
Security Coordination (ODESC) is the committee of government chief executives charged with providing strategic policy advice to ministers on such matters. ODESC oversees the areas of emergency readiness, intelligence and security, terrorism and maritime security. The chief executive of the department of Prime minister and cabinet chairs the committee, and members are the chief executives from relevant government agencies (Fig.2). The diagram below outlines the national crisis management arrangements that operate for any emergency.

New Zealand has published a strategy document outlining its regional and local Disaster Management system. The purpose of this strategy paper is to set out the vision, values, principles and objectives for civil defense emergency management (CDEM) in New Zealand. This strategy is part of the CDEM framework in New Zealand. The CDEM act 2002 (the law), the strategy, the national CDEM Plan (Plan), the national CDEM Plan guide (guide), and the CDEM group plans all form part of the framework with the support and participation of the center. Local government, emergency services, lifeline services, other general infrastructure providers, businesses, and voluntary organizations that enforce CDEM regulations. To achieve a resilient New Zealand these arrangements are illustrated in Fig.3. Local and regional cooperation and coordination is essential and a cornerstone of action, strategy and plan and guidance.

\subsection{Philippines}

Located in Southeast Asia, the Philippines is one of the largest island groups in the world, comprising more than 7,000 islands. Located at the edge of two tectonic plates, the Philippines ranks 4th in the list of countries most prone to natural disasters based on UNISDR's 20-year assessment. Philippines; It is exposed to various natural disasters such as earthquakes, volcanic eruptions, landslides, floods, droughts and typhoons.

The country has a tropical climate. The country is vulnerable to extreme weather events as it is located in the Pacific Typhoon Belt. Some of the devastating floods and landslides are triggered by typhoons that occur. Other factors triggering landslides are volcanic eruptions, earthquakes and increased monsoon precipitation. Wide coastlines also cause disasters such as tsunami, flood, landslide and drought. Since the country is located in the Pacific Earthquake Belt, it is frequently exposed to earthquakes and volcanic activities (Doroteo 2015). 8 of the 10 cities in the world most exposed to natural disasters are located in the Philippines. This is evident in the estimated $\$ 23$ billion in damage and the loss of 70,000 Filipinos in 565 natural disasters. Total losses from natural disasters are estimated to cost the Philippines $\$ 6.5$ billion each year (World Economic Forum 2016). The National Disaster Risk Reduction and Management Council of New Zealand (NDRRMC), formerly known as the National Disaster Coordinating Council, has expanded its membership and functions to deal with the complexities of today's disasters. Philippine disaster risk reduction and management structure is shown in Fig. 4.

NDRRMC; According to the law numbered RA 10121, the national council is the main coordinator of disaster management, with the tasks of policy making, coordination, supervision, monitoring, and evaluation for disasters or emergency. The NDRRMC is the primary policy-making body for coordination, integration, supervision, monitoring, and evaluation, including the law. (Azuela et al. 2020).

\subsection{Turkey}


Turkey is exposed to natural disasters such as earthquakes, floods, landslides, avalanches, droughts, forest fires and man-made disasters due to its high physical, social and economic vulnerability as well as its geological structure and climatic characteristics. Turkey is in the Mediterranean, Alpine, and Himalayan seismic belt, which is one of the most active seismic belts of the earth, and is located between three large tectonic plates such as Europe-Asia, Arabia and Africa, and two small plates such as the Aegean and Anatolian plates (Şengör and Yilmaz 1981).

This belt is an active zone in which approximately $20 \%$ of the earthquakes in the world occur and causes a devastating earthquake in the country on average every five years (AFAD 2020). Turkey ranks first among OECD countries in terms of loss of life, property and economic losses caused by disasters. According to the statistical data of the last 60 years, losses caused by natural disasters, directly or indirectly, correspond to approximately 3-4\% of GDP. The Law No. 5902 on the Organization and Duties of the Disaster and Emergency Management Presidency, which was enacted in 2009 in order to eliminate the complexity and coordination problems in the disaster management system and to remove the multiheadedness, was adopted and entered into force after being published in the Official Gazette. In order to carry out and coordinate services linked to disasters and emergency, civil defense, and disaster management, three general directorates (General Directorate of Disaster Affairs, General Directorate of Civil Defense, and Turkey Emergency Management) were abolished under this law. Instead of these three main directorates, the Prime Ministry AFAD was formed to coordinate institutions and organizations prior to, during, and after the disaster. The organization chart of AFAD, which manages the process in disasters and emergencies in Turkey, is as follows in Fig.5.

\section{Methodology}

This study proposes a new approach to develop a tool for measuring disaster reduction plans in selected countries by synthesizing components covering disaster risk reduction studies at the national level using multi-criteria decision making. AHP is a decision-making methodology that can be used to address highly complex problems with a variety of scenarios, criteria and actors. This method has been applied in various studies designed to improve development in sectors (Saaty and Vargas 2012). These sectors could been such as energy, construction, natural resources, economics, business management, and disaster and risk management. In practice, the decision problem is first defined. Thus, the necessary data to be used during the analysis and solution of the decision problem were obtained to create the decision hierarchy. In the next process, a decision hierarchy is created including the purpose of the application problem, the comparison criteria and the alternatives to be compared, and the solution of the application problem is started. The methodology used in this study was generally carried out in 3 stages. The main aim is to understand how to evaluate the best DRR plan among country samples. In the second stage, the effective parameters that will include the sections in the Plans and the disaster management stages are chosen as the main criteria. Other parameters that explain these criteria in detail and feed the main criterion as a component are also determined as sub-criteria. Decision makers are faced with multiple alternatives while making their decisions in the process of examining the current plans and documents of the countries related to ARF. For this purpose, in order to understand which country the plan is more functional among the alternative countries at the last stage; a questionnaire was developed and the opinions of country experts were taken and the results 
were analyzed using the AHP method. Disaster management systems and disaster risk reduction plans of Japan, Turkey, Philippines and New Zealand, which are among the countries with high disaster risk, were examined. Many criteria were evaluated in the ARA plans and documents examined, and it was analyzed which of our alternatives Japan, Turkey, Philippines and New Zealand was more successful on a country basis (Fig.6).

\subsection{Analytical Hierarchy Process}

The Analytic Hierarchy Process (AHP) is a math and psychology-based method for organizing and analyzing complex decisions. The AHP was developed by Saaty (Saaty 1980). In the AHP Hierarchy Model, the top level of the hierarchy consists of a single item or goal, which is the overall goal. At the level below the goal, there are factors that affect and contribute to the decision, known as criteria or variables, in order to achieve the stated goal.

AHP would be the most appropriate method in terms of classification of data, compliance with strategic planning during the application of DRR plan principles, and comparison of other country sample plans according to target actions and criteria. At the next level, there are sub-criteria (if any) containing the details within the criteria (Fig. 7). There are alternatives with decision options at the lowest level in the hierarchy (Razmi, Rahnejat, and Khan 2000). In the application, firstly, the decision problem is defined. Here, the process of collecting information about the application problem is also mentioned. Thus, the necessary data to be used during the analysis and resolution of the decision problem, to create the decision hierarchy, were obtained. In the next process, a decision hierarchy was established that includes the purpose of the application problem, the comparison criteria and the alternatives to be compared, and the solution of the application problem was started.

After the hierarchical model is established, pairwise comparison matrices should be created in order to determine the importance of all criteria relative to each other. During the creation of the matrices, the relative importance of each pairwise comparison matrix is determined separately by the decision maker. In Table1, the relative importance of the criteria is determined by assigning values between "1" and "9" to the matrix and transforming the verbal values into numerical values (Wollmann et al. 2014).

Decision makers obtain the pairwise comparison matrix shown in Eq. 1 through the comparison scale given in Table 1 in the light of their value judgments, knowledge, experience and equipment.

$A=\left[\begin{array}{ccccc}a_{11} & a_{12} & a_{13} & \ldots & a_{1 n} \\ a_{21} & a_{22} & a_{23} & \ldots & a_{2 n} \\ a_{31} & a_{32} & a_{33} & \ldots & a_{3 n} \\ \vdots & \vdots & \vdots & \ldots & \vdots \\ a_{n 1} & a_{n 2} & a_{n 3} & \ldots & a_{n n}\end{array}\right]$

A: Pairwise comparison matrix

$\mathrm{n}=$ Number of criteria in evaluation

$a_{i j}=$ importance of criterion $i$ over criterion $j$

In the binary comparison matrix, the sums of each column will be taken and the matrix will be normalized by dividing each value in the matrix by the related column sum and ensuring that the sum of the values in each column is 1.00 . The comparison matrix shows the importance 
levels of the criteria relative to each other within a certain logic. Column vectors forming the comparison matrix are used to determine the weights (percentage importance distributions) of these criteria. B column vectors with $\mathrm{n}$ and $\mathrm{n}$ components are created. B column vectors are calculated with the help of the formula shown in Eq. 2.

$$
b_{i j}=\frac{a_{i j}}{\sum_{i=1}^{n} a_{i j}}
$$

When the above-mentioned steps are repeated for other criteria, B column vectors will be obtained as much as the number of criteria (Eq. 3).

$$
B_{1}=\left[\begin{array}{c}
b_{11} \\
b_{21} \\
\vdots \\
\vdots \\
b_{n 1}
\end{array}\right]
$$

B column vectors are combined in a matrix format, the $\mathrm{C}$ matrix shown in Equation 4 below will be formed.

$$
C=\left[\begin{array}{ccccc}
c_{11} & c_{12} & c_{13} & \ldots & c_{1 n} \\
c_{21} & c_{22} & c_{23} & \ldots & c_{2 n} \\
c_{31} & c_{32} & c_{33} & \ldots & c_{3 n} \\
\vdots & \vdots & \vdots & \ldots & \vdots \\
c_{n 1} & c_{n 2} & c_{n 3} & \ldots & c_{n n}
\end{array}\right]
$$

After the normalized pairwise comparison matrix is created, the criteria weights are obtained by taking the arithmetic average of the row values in the $\mathrm{C}$ matrix. Thus, the $\mathrm{W}$ column vector, also called the eigenvector, is obtained (Eq. 5).

$$
W=\left[\begin{array}{c}
W_{1} \\
W_{2} \\
\vdots \\
\vdots \\
W_{n}
\end{array}\right]
$$$$
W_{i}=\frac{\sum_{j=1}^{n} c_{i j}}{n}
$$

Although the AHP method has a consistent systematic, the accuracy of the results will depend on the consistency of the criteria in comparison by the decision maker. The Consistency Ratio (CR) should be calculated for the pairwise comparison matrices, allowing the consistency of the AHP method to be measured after the comparisons between the criteria and the determined priorities. In order to calculate the $\mathrm{CR}$ value, first of all, the coefficient called "Consistency Index (CI)", which is one of the many methods, should be calculated in order to determine whether a matrix $\mathrm{A}$, which is formed as a result of pairwise comparison judgment, is consistent. The CI coefficient is calculated by the formula given in Eq. 6 . 
$C I=\frac{\lambda_{\max }-n}{n-1}$

363

364

365

366

367

In order to calculate the CI value, the largest eigenvector of the matrix, that is $\lambda$ max, must be calculated. The formula in Eq. 7 is used to calculate the value of $\lambda \max$ given in Eq. 6.

$\lambda_{\max }=\frac{1}{n} \sum_{i=1}^{n}\left(\frac{\sum_{j=1}^{n} a_{i j}{ }^{*} w j}{w_{i}}\right)$
(Eq.7)

368 For the calculation of $\lambda \max$, firstly, the D column vector shown in Eq. 8 is obtained 369 from the matrix multiplication of the comparison matrix $\mathrm{A}$ and the priority vector $\mathrm{W}$.

(Eq.8)
As defined in the formula above, the $\mathrm{E}$ value for each evaluation criterion is found from the division of the reciprocal elements of the $\mathrm{D}$ column vector and the $\mathrm{W}$ column vector found. In the formula given in Eq.9-10, which is the arithmetic mean of these values, it gives the basic value $\left(\lambda_{\max }\right)$ for the comparison.

$$
\begin{aligned}
E_{i} & =\frac{x_{i}}{w_{i}} \quad i=1,2, \ldots, n \\
\lambda_{\max } & =\frac{\sum_{i=1}^{n} E_{i}}{n}
\end{aligned}
$$

After calculating the CI value with the help of the formula shown in Equation11, the randomness indicator (RI) values, which consist of fixed values according to the number of criteria (n) used for different matrix sizes in the pairwise comparison, are given in Table 2 to complete the calculation of the CR value (Saaty, 1990).

After CI and RI values are determined, "CR" is calculated.

$$
C R=\frac{C I}{R I}
$$

Based on the upper limit of CR $0.1(\mathrm{CR} \leq 0.1)$, the consistency level of the pairwise comparison matrix is acceptable for the reliability of the results; If the CR value is greater than 0.1, the consistency level cannot be accepted due to the inconsistency of the decision maker's judgments. In this case, the decision maker should review the criteria values and repeat the steps of the AHP method described above and recalculate the consistency test (Karaburun, 2018).

$$
A x W=\left[\begin{array}{ccccc}
a_{11} & a_{12} & a_{13} & \ldots & a_{1 n} \\
a_{21} & a_{22} & a_{23} & \ldots & a_{2 n} \\
a_{31} & a_{32} & a_{33} & \ldots & a_{3 n} \\
\vdots & \vdots & \vdots & \ldots & \vdots \\
a_{n 1} & a_{n 2} & a_{n 3} & \ldots & a_{n n}
\end{array}\right] x\left[\begin{array}{c}
W_{1} \\
W_{2} \\
\vdots \\
\vdots \\
W_{n}
\end{array}\right]=D=\left[\begin{array}{c}
x_{1} \\
x_{2} \\
\vdots \\
\vdots \\
x_{n}
\end{array}\right]
$$


After the previous steps were calculated for all levels in the AHP method, the mx1-size $S$ column vectors (Eq. 12) created according to the importance values of the $\mathrm{n}$ criteria to the alternatives calculated separately for each criterion were brought together and the pairwise comparison matrix of the $\mathrm{m} \mathrm{x} \mathrm{n}$-size alternatives and criteria was Durbin-Watson (DW) decision matrix is obtained (Eq.13).

Finally, with the help Eq. 13, the L column vector (Eq. 14) is created by adding the row in which it is found by multiplying the value of each alternative in the alternatives matrix with the weight score of that criterion. The L column vector represents the percentage distribution of decision options, and the sum of the values in the vector is 1 . The decision option with the highest weight in this vector is determined as the decision option that should be preferred for solving the problem. (Eq. 14) In the application part of the thesis, it will be tried to determine the efficiency levels of each of them and which ones should be taken into account while creating these plans as a result of comparing the parameters that can be effective in the DRR plans by using the AHP method.

$$
D W x W=L=\left[\begin{array}{cccc}
s_{11} & s_{12} & \ldots & s_{1 n} \\
s_{21} & s_{22} & \ldots & s_{2 n} \\
\cdot & & & \cdot \\
\cdot & & & \cdot \\
\cdot & & & \cdot \\
s_{m 1} & s_{m 2} & \ldots & s_{m n}
\end{array}\right] x\left[\begin{array}{c}
w_{1} \\
w_{2} \\
\cdot \\
\cdot \\
\cdot \\
w_{n}
\end{array}\right]=\left[\begin{array}{c}
l_{11} \\
l_{21} \\
\cdot \\
\cdot \\
\cdot \\
l_{m 1}
\end{array}\right]
$$

\subsection{Determination of Criteria}

Within the scope of the study, the criteria in the DRR strategies and plans of the countries that are the subject of the analysis were examined and criteria selections were made. Among the 
objectives to be achieved with this study is to investigate whether there is an effective way to evaluate country DRR plans. Are there gaps between "expectations (ie expected targets)" and "actual performance" in country plans provided by different countries? Do policy makers give the same weight or priority to each key action (and mandate) in their documents? In line with the determined targets, it is expected that the results of empirically evaluating country plans with AHP, which is one of the multi-featured decision-making processes, will be examined with this study. The components that best described a disaster risk reduction plans were presented on a four-tier hierarchy representing relevant aspects of natural disaster management in an AHP model where in the top tier represented a goal related to the problem. The second tier consisted of seven criteria determined based on risk reduction components. Third-tier, for each criterion characterizing disaster risk reduction plans represented by represented by 36 important components third tier are determined. Last tier is represented by alternative countries (Fig.8).

432

433

434

435

436

437

438

439

440

441

442

443

444

445

446

447

448

449

450

451

452

453

454

455

456

457

458

459

460

461

462

463

464

465

466

467

468

The seven main criteria determined are as follows: Risk Identification (B1), Risk Reduction (B2), Response and Recovery (B3), Economic Disaster Risk Management (B4), Disaster Preparedness (B5), Governance (B6) and Compliance of Policies and Plans (B7), were selected as the main criteria. 36 important components of the main criteria, which explain each one in detail and systematically cover the process, were chosen as sub-criteria (Fig.9). The first set of pairwise comparison matrices was evaluated by experts in terms of relative importance of the work to the seven main DRR plan sections, based on both the expectations contained in the plans and actual performance.

\subsubsection{Risk Identification}

Risk identification is an important component of disaster risk management. Models, maps, indexes, etc., which are important for decision makers, to recognize and size the existence of disaster losses and to intervene in risk should be represented by Risk identification; Provides tools to evaluate specific policies and measures needed to develop DRR plans and strategies. The sub-criteria representing the risk identification are listed below;

- Systematic Disaster and Loss Inventory - Data Collection - Data Bank

- Hazard Monitoring and Estimation Methods

- Hazard Assessment and Mapping Systems

- Vulnerability and Risk Assessment Analysis

\subsubsection{Risk Reduction}

Disaster risk management specifically aims to reduce risk. It is the act of foresight to prevent or reduce the economic, social and environmental impacts of potentially dangerous physical events. It refers to the planning processes, the implementation of measures that change the existing risk conditions and, where possible, hazard control. The sub-criteria representing risk reduction are listed below;

- Considering DRR in Land Use and Urban Planning

- Hydrological Basin Intervention and Environmental Protection (Flood/Flood Prevention Structures)

- Making Critical Facilities Disaster Resistant

- Development of Information and Decision Support Systems in Disaster Risk Management

- Building Stock - Updating Safety Standards and Building Rules

- Strengthening and Upgrading Public and Private Assets

- Development of Forecasting and Early Warning Systems 


\subsubsection{Response and Recovery}

Response activities in disaster risk management include the rapid identification of the disaster situation and emerging needs, the ability to establish multi-directional communication with stakeholders, the rapid access of sufficient number of correct equipment and equipped personnel to the disaster site, the work of emergency health services and daily life support teams. On the other hand, DRR approaches aim to ensure that those who are exposed to disasters return to their normal lives as soon as possible, to rebuild the structures in disasterresilient ways, and to create a disaster-resilient society by taking the state of development to an advanced level. Sub- criteria representing intervention and improvement are listed below;

- Organization and Coordination of Emergency Operations

- Emergency Response Planning

- Logistics System Planning and Equipment, Vehicle and Infrastructure Equipment

- Simulation, Inter-Agency Intervention Testing and Updating

- Integration of DRR into Recovery and Reconstruction Planning Processes

\subsubsection{Economic Disaster Risk Management}

Expenditures made to return the system, which is deteriorated / lost due to disasters at any time, to normal as soon as possible, and the management of existing resources is expressed as "Disaster Economy". The place of disaster economy in DRR is the management part of the budget allocated for risk reduction measures and measures before disasters occur. In order for DRR to be sustainable, it is necessary to determine the economic losses caused by disasters and to know the investments made here. Disasters cause serious effects on development, public finance and growth in developing countries such as Turkey. For this purpose, quality and reliable information is required for monitoring investment budgets and determining the economic losses that occur in disasters. The international community supports this issue with global and regional research and information systems on the economic management of disaster risks. The sub- criteria representing the economic management of disaster risks are listed below;

- Conducting Studies on the Economic Results of Investments Made in DRR

- Allocating Resources (Funds) for Institutional Strengthening

- Budget Allocation and Mobilization

- Implementation of Social Safety Nets and Intervention with Funds

- Insurance Coverage of Public Assets

- Housing and Private Sector Insurance and Repetitive Insurance Coverage

\subsubsection{Disaster Preparedness}

Disaster preparedness refers to the measures taken to be prepared for disasters and to reduce the effects of disasters. In other words, reducing the risks of disasters and preventing them whenever possible, reducing their effects on vulnerable individuals and responding to their consequences quickly and dealing with them effectively are one of the most fundamental steps in the DRR system. In the disaster preparedness system; Starting from the individual, bringing a culture of disaster preparedness to all segments of the society, raising awareness in individuals, ensuring their participation in volunteer activities, teaching the basic precautions that individuals can take in the places they live, incorporating DRR into the education system, ensuring that individuals learn and practice the correct behavior in disasters with exercises, It is aimed to expand the places where the sectors can receive disaster education and to establish infrastructures that they can easily access, to standardize the disaster education given through various channels throughout the country, to participate in the studies carried out by international organizations and to create accredited education paths with sufficient knowledge and experience. Sub- criteria representing disaster preparedness are listed below; 
- Increasing Community Awareness and Capacity on DRR

\subsubsection{Governance}

Disaster risk governance defines it as the way of coordinating the authorities responsible for DRR, public institutions and organizations, media, private sector, non-governmental organizations, universities at regional, national and international levels to manage and reduce the risks related to disasters. The sub- criteria that examine the different governance issues related to DRR from global, regional, national and local perspectives and represent the needs of disaster governance at different levels are listed below;

- Interagency, Multisectoral and Decentralized Organization

- Legislative Infrastructure Regarding DRR

- Presence and Consolidation of the DRR National Platform

- International Cooperation for DRR

- Existence of Gender Responsive DRR Strategies

\subsubsection{Compliance of Policies and Plans}

In order to strengthen the DRR plans, integrate them with the response stages, and be better prepared for disasters, it is essential that all policies in the field of DRR and all documents on a global scale are compatible with country strategies. Communities become more resilient to disasters with the implementation of the goals and objectives included in the DRR plans. If a country's sustainable development goals include the existence of local plans, adaptation policies to existing climate change agreements, and adaptation programs to global-scale strategies, the easier it is to implement DRR mechanisms. The existence of these plans and policies, their periodic evaluation and the creation of monitoring and evaluation systems that will report to the public, can be measured by their effects on DRR processes. For this reason, the sub- criteria representing the Compliance of Policies and Plans are listed below;

- Integrating Climate Change Policy, Plans and Adaptation Programs with the DRR Strategy

- Availability of Local Level DRR Plans

- Compliance of the DRR Plan with the Post-2015 Agenda (Sendai, Sustainable Development Goals, etc.)

- Preparation of Business Continuity Plans

\section{Discussion}

After the criteria were determined, a 4-level hierarchical structure consisting of purpose, main-criteria, sub-criteria and alternatives was created as follows. The purpose at the top level of the hierarchical structure is stated as "Choosing a Disaster Risk Reduction Plan". At the second and third levels, there are main criteria and sub-criteria in accordance with the purpose. At the lowest level, the countries whose DRR plans are examined are listed as alternatives-hierarchical model (Fig.10).

Among main criteria, B1 (Risk Identification), B2 (Risk Reduction), B3 (Response and Recovery), B4 (Economic Management of Disaster Risks), B5 (Disaster Preparedness), B6 (Governance), B7 (Compliance of Policy and Plans). As can be seen in Fig.10a, the order of 
importance is B2, B1, B3, B4, B5, B6, B7, starting from the highest. Risk Reduction" has the highest weight among the main criteria.

As can be seen in Fig.10b; Ranking of importance among our risk identification sub-criteria RI1 (Systematic disaster and loss inventory-Data collection-Data bank), RI2 (Hazard monitoring and estimation methods), RI3 (Hazard assessment and mapping systems), RI4 (Vulnerability and risk assessment analysis) RI2, RI1, RI3, RI4, starting from the highest.

As can be seen in Fig.10c, Risk reduction sub-criteria RR1 (Considering DRR in land use and urban planning), RR2 (Hydrological basin response and environmental protection (Flood/Flood prevention structures), RR3 (Making critical facilities disaster resistant), RR4 (Development of information and decision support systems in disaster risk management), RR5 (Building stock - Updating safety standards and construction rules), RR6 (Strengthening and upgrading public and private assets), RR7 (Development of forecasting and early warning systems) from high to RR1, RR7, RR2, RR3, RR6, RR4, RR5 respectively.

As can be seen in Fig.10d, response and recovery sub-criteria RE1 (Organization and coordination of emergency operations), RE2 (Emergency response planning), RE3 (Logistics system planning and equipment, Vehicle and Infrastructure equipment), RE4 (Simulation, Inter-Agency Intervention Testing and Updating), RE5 (Integration of DRR into recovery and reconstruction planning processes), starting from the highest order of importance, RE3, RE1, RE5, RE2, RE4 respectively.

As can be seen in Fig.10e, our sub-criteria of economic management of disaster risks are EM1 (Conducting Studies on the Economic Results of Investments Made in DRR), EM2 (Allocating Resources (Funds) for Institutional Strengthening), EM3 (Budget allocation and mobilization), EM4 (Implementation of social safety nets and intervention with funds), EM5 (Insurance coverage of public assets), EM6 (Housing and private sector insurance and repetitive insurance coverage) in order of importance EM2, EM3, EM6, EM5, EM1, EM4 respectively, starting from the highest.

As can be seen in Fig.10f, among our disaster preparedness sub-criteria, DP1 (Increasing community awareness and capacity on DRR), DP2 (Developing DRR trainings based on priorities determined for main sectors), DP3 (Inclusion of DRR in the education and training program), DP4 (Coordination and cooperation of volunteer activities), DP5 (Performing exercises and simulations), starting from the highest order of importance, were DP3, DP1, DP5, DP2, DP4, respectively.

As can be seen in Fig.10g, our Governance sub-criteria DG1 (Interagency, multi-sectoral and decentralized organization), DG2 (Legislative infrastructure regarding DRR), DG3 (Presence and consolidation of the DRR national platform), DG4 (International cooperation for DRR), DG5 (Existence of gender responsive DRR strategies) starting from the highest order of importance, were DG5 DG3, DG2, DG1, DG5, DG4.

As can be seen in Figure 10h, among our sub-criteria of compliance of policies and plans, PP1 (Integrating climate change policy, plans and adaptation programs with the DRR strategy), PP2 (Availability of local level DRR plans), PP3 (Compliance of DRR Plan with post 2015 agenda (Sendai, Sustainable Development Goals etc.), PP4 (Preparation of business continuity plans), starting from the highest order of importance, were PP2, PP3, PP4, PP1 respectively. 
The plans and strategies of the selected countries for DRR were examined, and 4 countries were ranked with a holistic approach using the AHP methodology in line with the main ranking of the countries changes and the general evaluation results of the countries are as in Table 3.

The determined criteria and sub-criteria were sent to the experts in the field of DRR by e-mail and the countries were asked to be scored. Scoring systematic "Full score: 1; Good level: 0.75; Intermediate: 0.50; Limited application: 0.25; No application: 0" and the general result of the hierarchical structure of the model was obtained as a result of the multiplication of the weights of the criteria. After evaluating the existence of the main criteria and sub-criteria weighted using the AHP methodology in these 4 country plans by the experts of the countries, the success ranking of the countries was made (UNISDR 2015) .

\section{Conclusion}

Within the scope of the study, disaster management systems and disaster risk reduction plans of Japan, Turkey, Philippines and New Zealand, which are among the countries with high disaster risk, were examined. It is now firmly accepted that a comprehensive DRR plan is necessary for any country in the world to be considered successful in disaster management. A number of monitoring and evaluation systems have been developed to assess the success of national plans, but limited work has been done to synthesize the components that make up these systems and to select the most important ones to use.

It is both practical and less time-consuming to plan locally and see the functionality of the plan in situ. However, more comprehensive and multi-criteria decision-making methods should be used when evaluating the effectiveness of a national plan. For this purpose, within the scope of the thesis study, the criteria in the DRR strategies and plans were examined, and the country strategies, practices and policies based on the implementations were evaluated.

There is a concept that is generally accepted in the world. DRR offers a high return on investment: One dollar invested in disaster prevention can save seven dollars' worth of disaster related economic losses. In this context, DRR is the first and most important stage in the disaster cycle. Each country's DRR strategy and plans may have different stages of importance. These differences both reveal country approaches and help us measure country success.

Knowing, defining, understanding and measuring disaster risks, conducting disaster risk management from the center, existence of effective intervention and improvement works, having a planned policy towards being a disaster prepared society are clearly the most basic pillars of DRR in a country. In this study, Risk Identification (B1), Risk Reduction (B2), Response and Recovery (B3), Economic Management of Disaster Risks (B4), Disaster Preparedness (B5), Governance (B6) and Compliance of Policies and Plans (B7) are included in the DRR processes) were chosen as the main criteria.

Multi-criteria decision making method was used to identify and synthesize the Interrelationships of these basic components of disaster management. The process (AHP) method, which includes paired pairwise comparisons of various alternatives, was chosen as the facilitating method. This method offers a versatile approach to decision makers in solving problems and determining the order of importance of effective parameters when more than one criterion is involved in the decision-making process. 36 important sub-components of the main criteria were selected as sub-criteria. As a result of the weighting, the importance levels of the parameters were determined as B2, B1, B3, B4, B5, B6 and B7, respectively. 
The importance of the sub-components is; it is of great importance in the evaluation of projects and policies that countries carry out based not only on the success of the existence of their plans, but also on the general plan. Because it is a very superficial approach to say that every country that has a DRR plan is successful in DRR. For example, is the Risk Identification parameter more important in the DRR system or is it the Risk Reduction processes? Expert opinions decide which parameter is important in this binary selection. Then, when evaluating for country

A, the sub-criteria of the main parameter are looked at. If country A has existing projects, strategies and policies covering the relevant parameter, all these are used in the success evaluation of country A. In this evaluation, a scoring technique was used for the final success classification of the countries examined.

This scoring is also applied in the online system to monitor the number of countries that have adopted and implemented national DRR strategies in accordance with the Sendai Disaster Risk

681 Reduction Framework 2015-2030. Indicators have been proposed to measure the presence or quality of each key element in countries' national DRR strategies, so that the indicator can measure the level at which national DRR strategies are aligned with the Sendai Framework. Sendai Member States will assess the level of implementation for each key element and enter all information into the web-based Sendai Framework Monitor. Countries are compared according to a certain weighting, since each element can be composed of many subcomponents in itself. Although a simple measure, it will enable countries to assess gradual or partial progress compared to the baseline and thus monitor the improvement in the quality of the national DRR strategy over time (UNISDR 2017)

The same scoring system was used in this study. The determined criteria and sub-criteria were sent to the experts in the field of DRR by e-mail and the countries were asked to be scored. Scoring systematic "Full score: 1; Good level: 0.75; Intermediate: 0.50; Limited application: 0.25; No-application: 0 " and the general result of the hierarchical structure of the model was obtained as a result of the multiplication of the weights of the criteria. After evaluating the existence of the main criteria and sub-criteria weighted by using the AHP methodology in these 4 country plans by the experts of the countries, the success ranking of the countries was made. At the end of the analysis, Japan was determined as the country with the best DRR plan and implementation, while our country was ranked 2nd, New Zealand ranked 3rd and Philippines ranked $4^{\text {th }}$ (Fig. 11)

With reference to the AHP combination of this model, Process and outcome components, and a composite index was designed for decision makers interested in disaster risk reduction planning. It is for those who want to reduce the risks arising from hazards and respond to hazards more effectively and analytically. Countries have prioritized approaches to DRR in recent years because of their progressive approach to disaster management. For this purpose, they make plans more seriously. This study will be an important reference for the countries that will make a new DRR plan, as the place of the plans in practice should be understood more clearly and which stage should be given more importance. This model is expected to minimize bias among country planning and contribute to how the DRR plan is measured quantitatively. 


\section{References}

AFAD. 2016. Açıklamalı Afet Yönetimi Terimleri Sözlüğü. ANKARA/TURKEY: Afet ve Acil

AFAD. 2020. Afet Yönetimi Kapsamında 2019 Yılına Bakış ve Doğa Kaynaklı Olay Istatistikleri. Ankara,Turkey.

Akyel, R. 2007. "Afet Yönetim Sistemi: Türk Afet Yönetiminde Karşılaş1lan Sorunların Tespit ve Çözümüne Ilişkin Bir Araştırma.” Çukurova Üniversitesi.

Azuela, Mary Jean, Dennis Paul Orge, Mary Grace Valdez, and Giselle Joy Esmeria. 2020. "Survey Design to Evaluate Healthcare System Resilience at Barangay Level in the Philippines." in Proceedings of the International Conference on Industrial Engineering and Operations Management. Vol. 0.

Baba, Hitoshi. 2013. Disaster Risk Management in Japan.

Britton, NR, and GJ Clark. 2000. "From Response to Resilience: Emergency Management Reform in New Zealand." Natural Hazards Review 1(3):145-50.

Cabinet Office. 2015. White Paper Disaster Management in Japan 2015.

Charlotte, Benson, Twigg John, and Tiziana Rossetto. 2007. Tools for Mainstreaming Disaster Risk Reduction: Guidance Notes for Development Organisations. Geneva.

Doroteo, H. J. 2015. "Disaster Risk Profile and Disaster Risk Management Framework of the Philippines: Natural Disasters." Pp. 1-46 in Erasmus Mundus Master in Public Health in Disasters. University of Oviedo.

ECHO. 2017. Disaster Risk Management. Brussels.

IPCU. 2014. Kentsel Risklerin Azaltılmast.

Jimee, Ganesh, Kimiro Meguro, and Amod Dixit Mani. 2019. "Learning from Japan for Possible Improvement in Existing Disaster Risk Management System of Nepal." Open Journal of Earthquake Research 08(02):85-100.

Kadığlu, Miktad. 2011. Afet Yönetimi Beklenilmeyeni Beklemek En Kötüsünü Yönetmek. İstanbul: Marmara Belediyeler Birliği.

Kelly, Charles. 1998. "Simplifying Disasters: Developing a Model for Complex Non-Linear Events." Australian Journal of Emergency Management 14(1):25-27.

MCDEM. 2019. National Disaster Resilience Strategy Rautaki Ā-Motu Manawaroa Aituā. Wellington.

Razmi, J., H. Rahnejat, and M. K. Khan. 2000. "The New Concept of Manufacturing 'DNA' within an Analytic Hierarchy Process-driven Expert System.” European Journal of Innovation Management 3(4):199-211.

Saaty, T. L. 1980. The Analytic Hierarchy Process. New York: McGraw-Hill.

Saaty, T. L., and Luis G. Vargas. 2012. "Models, Methods, Concepts \& Applications of the Analytic Hierarchy Process." International Series in Operations Research \& Management Science. 
Saunders, Wendy S. A., Scott Kelly, Suzanne Paisley, and Larissa B. Clarke. 2020. "Progress Toward Implementing the Sendai Framework, the Paris Agreement, and the Sustainable Development Goals: Policy from Aotearoa New Zealand." International Journal of

Saya, Setsuko. 2017. "Cabinet Office, Government of Japan (CAO)—Japan's International Cooperation on DRR: Mainstreaming DRR in International Societies." in Advancing Culture of Living with Landslides.

Şengör, A. M. Celâ., and Yücel Yilmaz. 1981. "Tethyan Evolution of Turkey: A Plate Tectonic Approach.” Tectonophysics 75(3-4).

Taştan, Bekir, and Arif Çağdaş Aydınoğlu. 2015. "Requirement Analysis for Determining Hazard and Vulnerability in Multiple Disaster Risk Management." Marmara Coğrafya Dergisi 31:336-97.

Ulutürk, G. 2006. "Local Administrations and Disaster Risk Management in Turkey." METU. UNISDR. 2015. Sendai Framework for Disaster Risk Reduction 2015 - 2030.

UNISDR. 2017. Technical Guidance for Monitoring and Reporting on Progress in Achieving the Global Targets of the Sendai Framework for Disaster Risk Reduction.

Wollmann, Dewey, Maria Teresinha Arns Steiner, Guilherme Ernani Vieira, and Patrícia Arns Steiner. 2014. "Details of the Analytic Hierarchy Process Technique for the Evaluation of Health Insurance Companies." Producao 24(3).

World Economic Forum. 2016. "The Global Risks Report 2016 | World Economic Forum." Journal of Sustainable Finance \& Investment 1(3). 
Figures

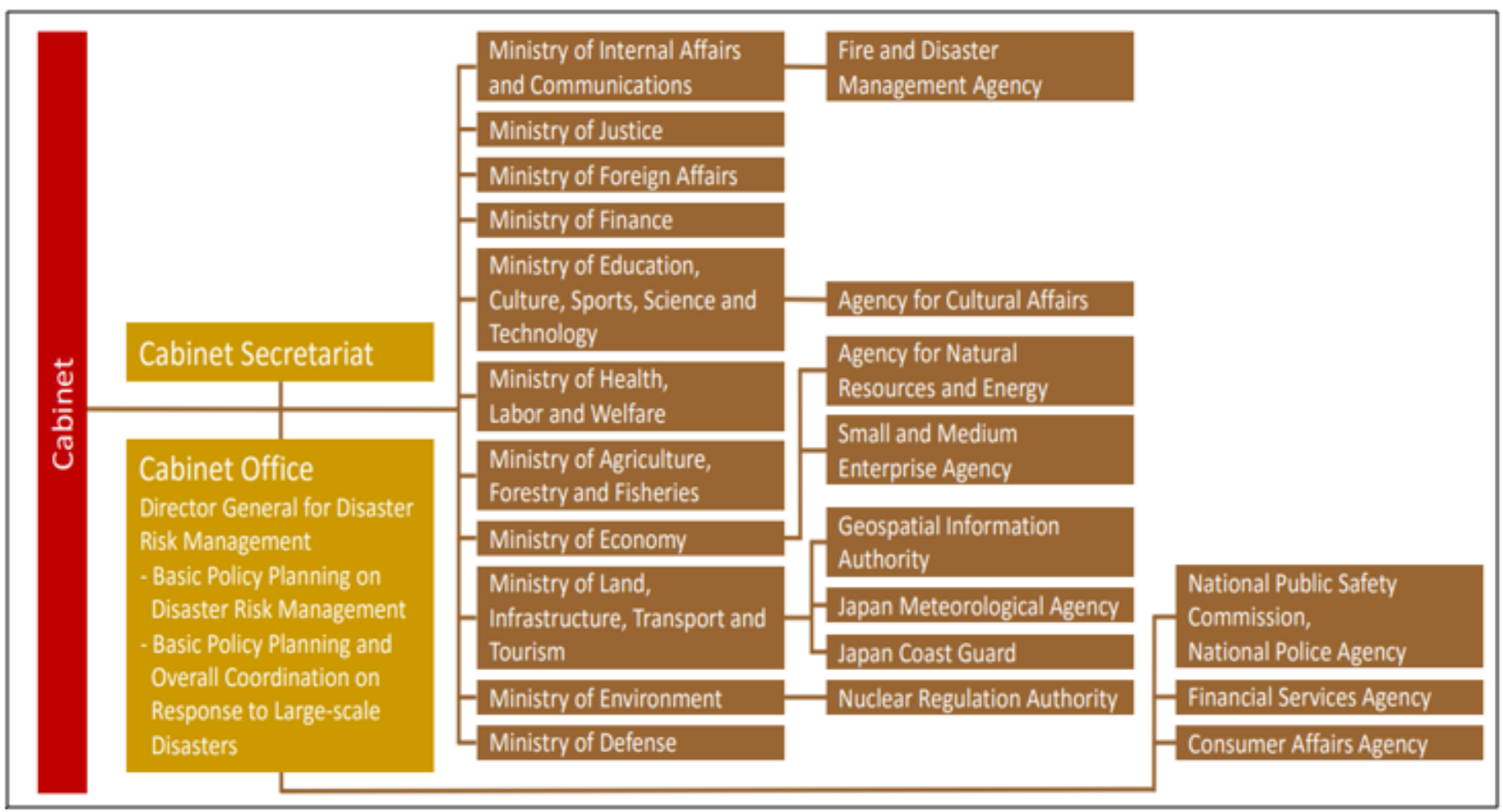

Fig. 1

\section{Figure 1}

In the Cabinet Office (Fig. 1), the Director General of Disaster Management, who is responsible for ensuring wide-ranging cooperation between relevant government agencies, is responsible for planning basic disaster management policies and carrying out overall coordination as well as large-scale disaster response (Saya 2017). 


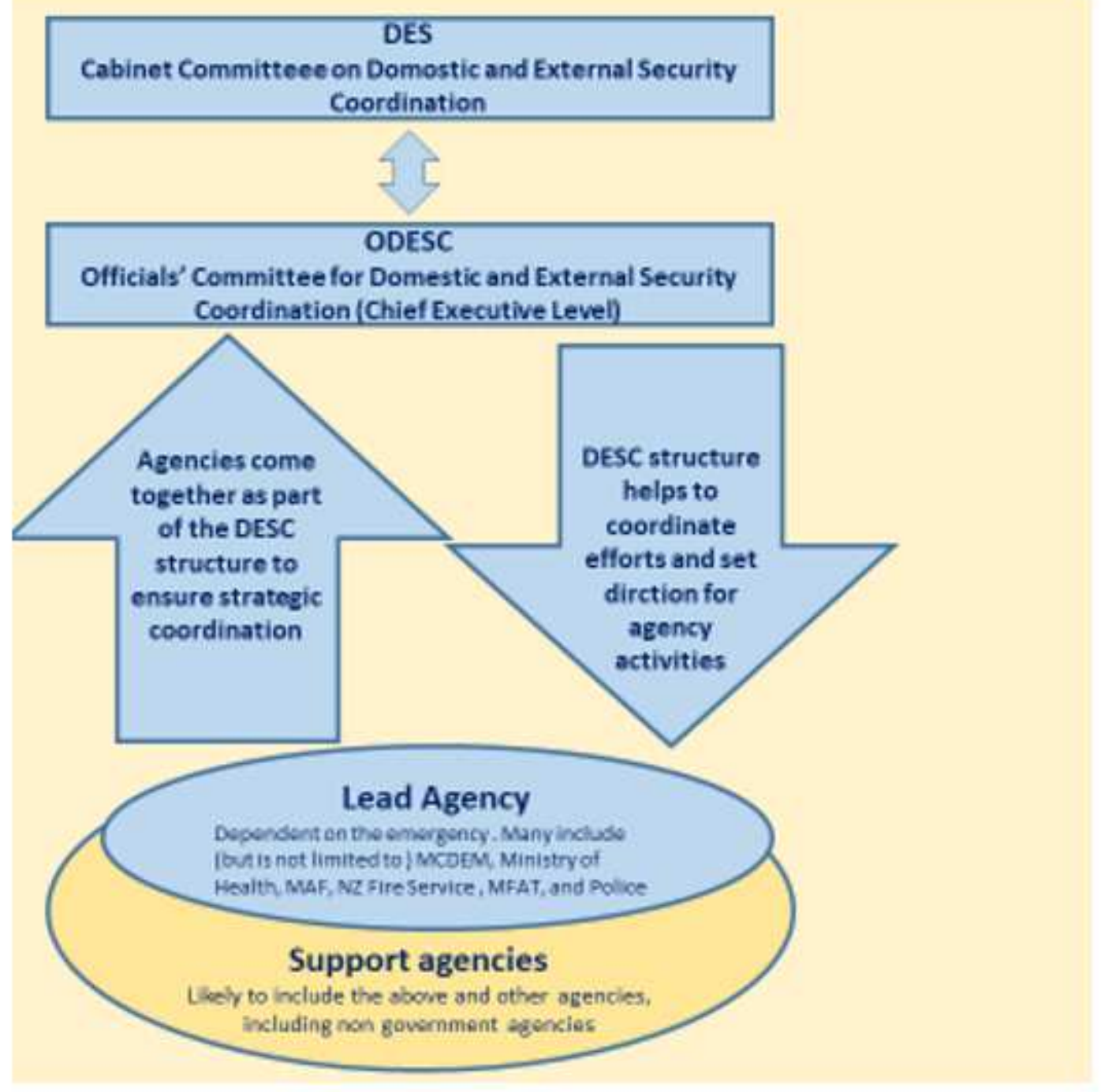

Fig.2

Figure 2

The chief executive of the department of Prime minister and cabinet chairs the committee, and members are the chief executives from relevant government agencies (Fig.2). The diagram below outlines the national crisis management arrangements that operate for any emergency. 
THE NEW ZEALAND CDEM FRAMEWORK

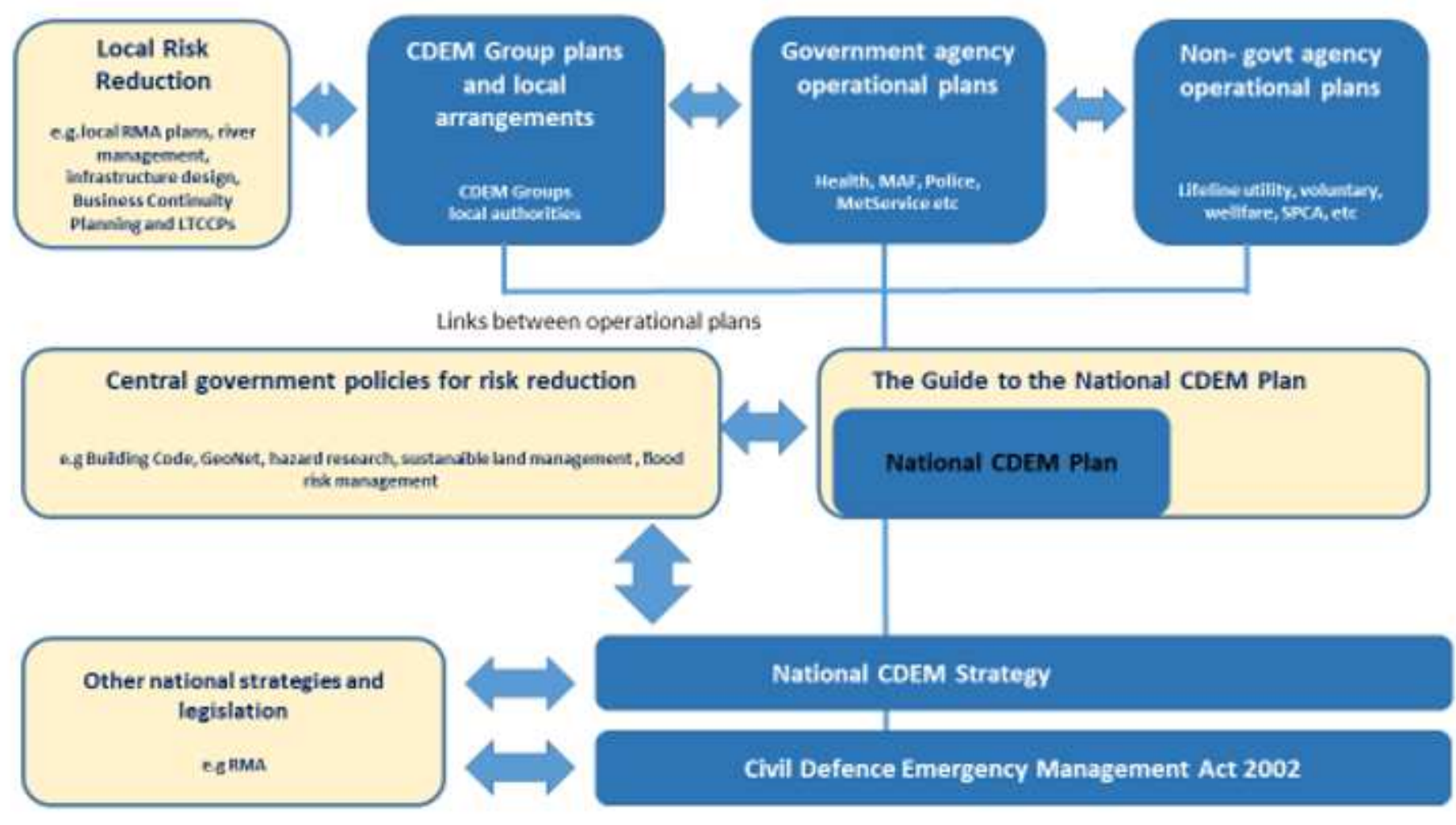

Fig.3

\section{Figure 3}

To achieve a resilient New Zealand these arrangements are illustrated in Fig.3. Local and regional cooperation and coordination is essential and a cornerstone of action, strategy and plan and guidance. 


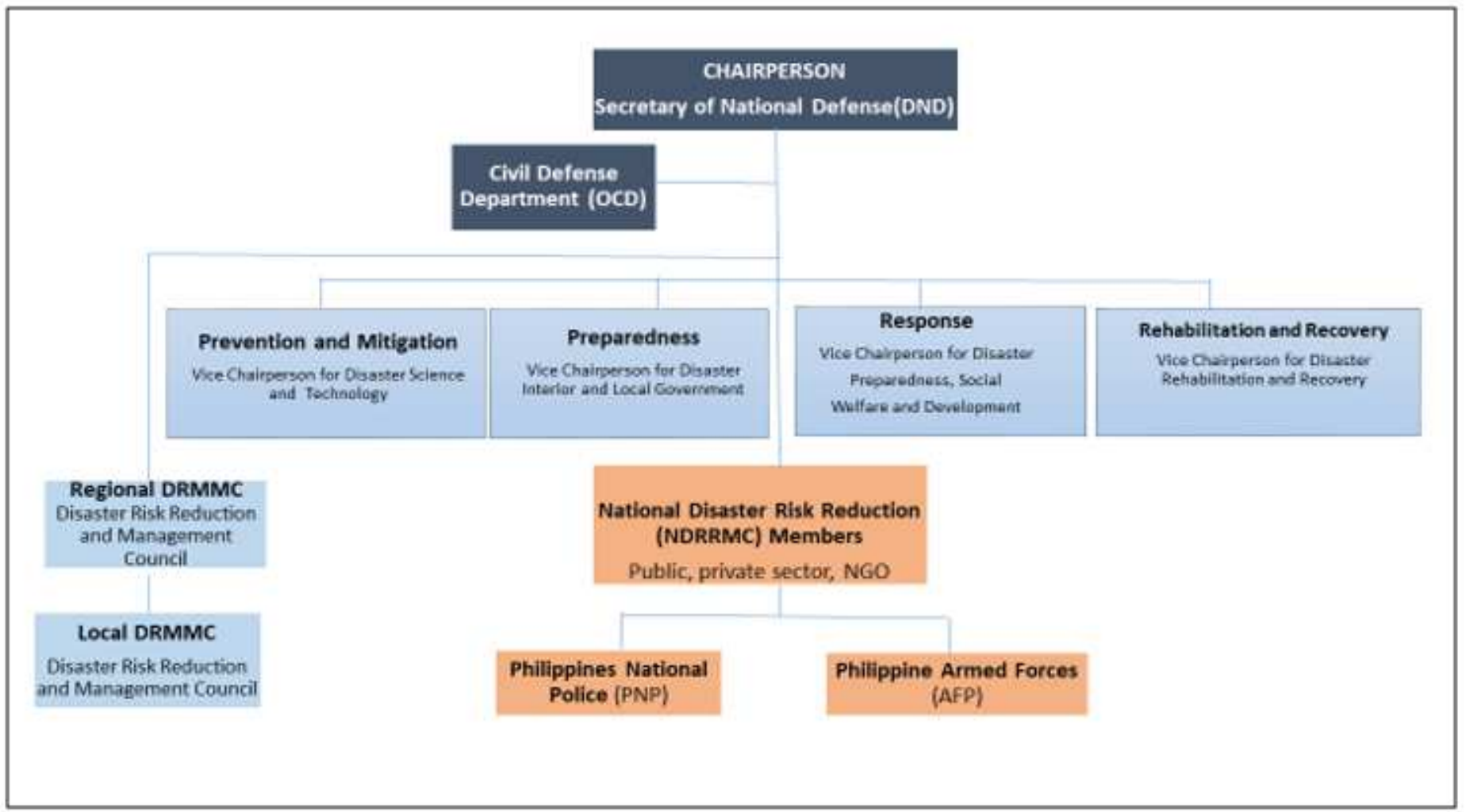

Fig.4

\section{Figure 4}

Philippine disaster risk reduction and management structure is shown in Fig. 4. 


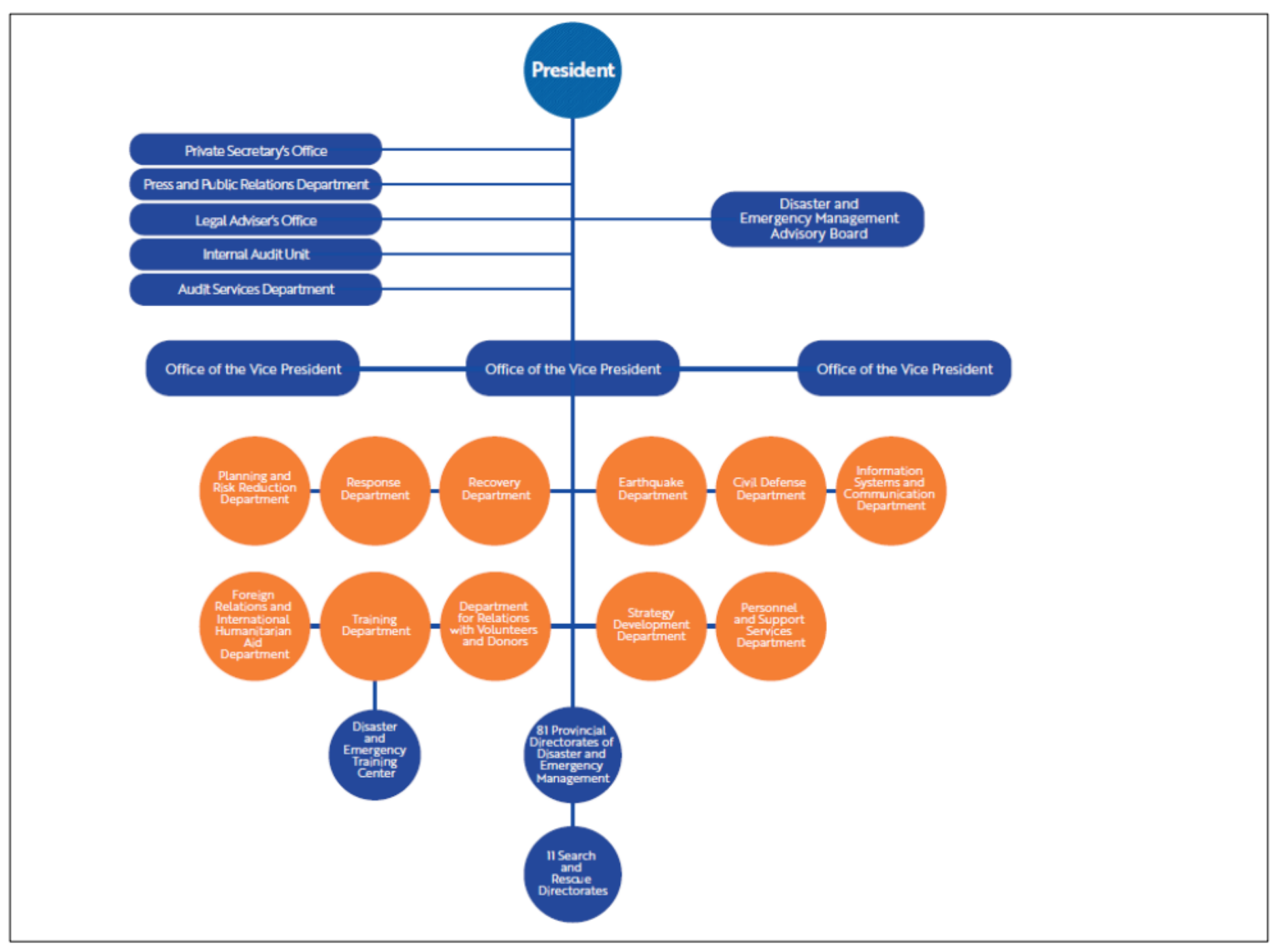

Fig.5

\section{Figure 5}

The organization chart of AFAD, which manages the process in disasters and emergencies in Turkey, is as follows in Fig.5. 


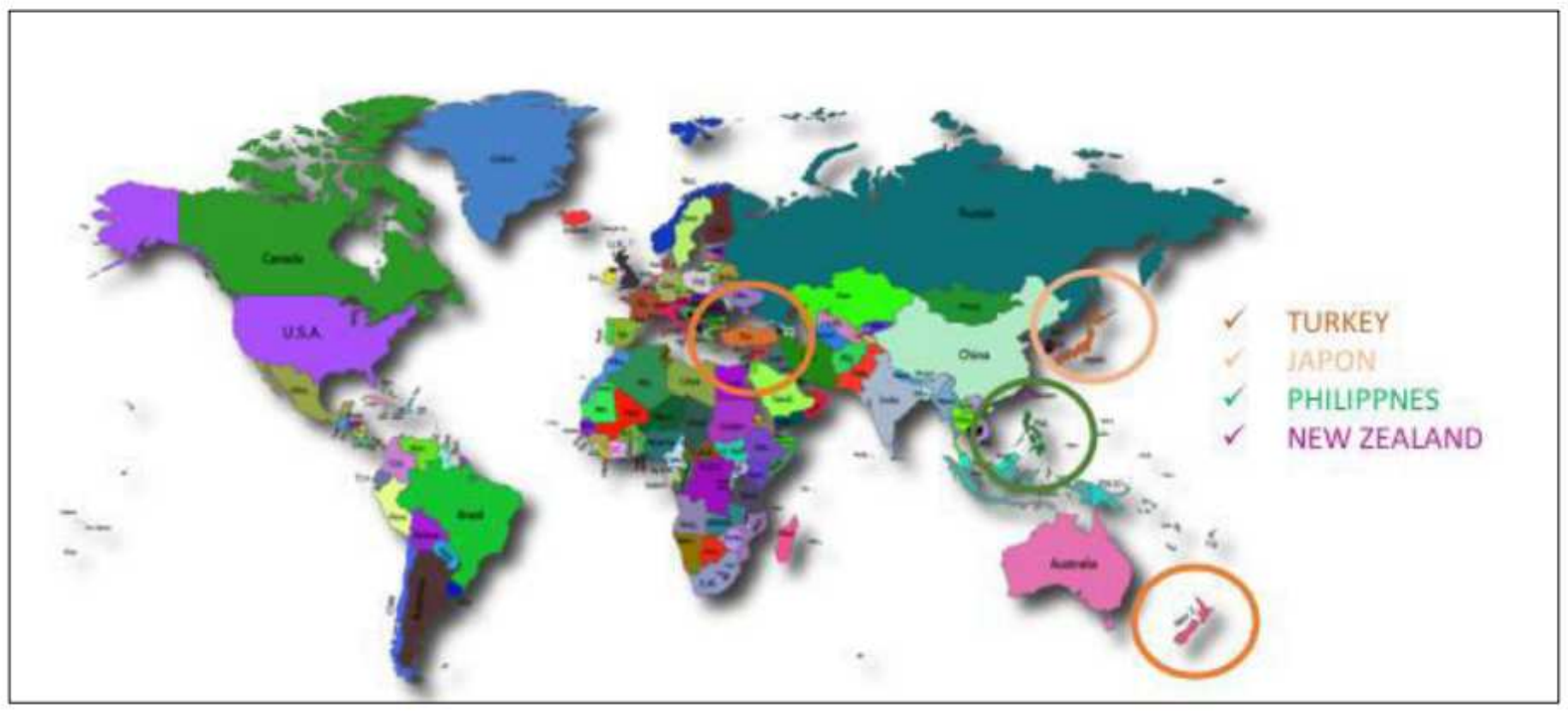

Fig.6

\section{Figure 6}

Philippines and New Zealand was more successful on a country basis (Fig.6).

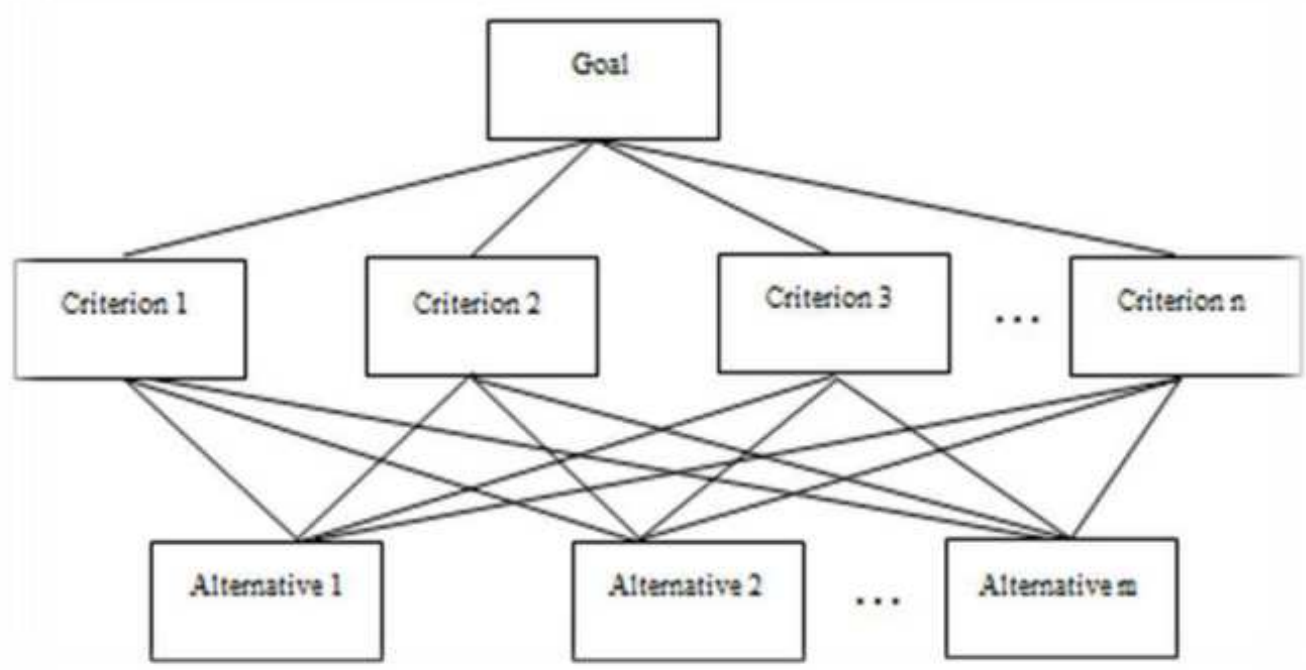

Fig. 7

Figure 7 
At the next level, there are sub-criteria (if any) containing the details within the criteria (Fig. 7). There are alternatives with decision options at the lowest level in the hierarchy (Razmi, Rahnejat, and Khan 2000).

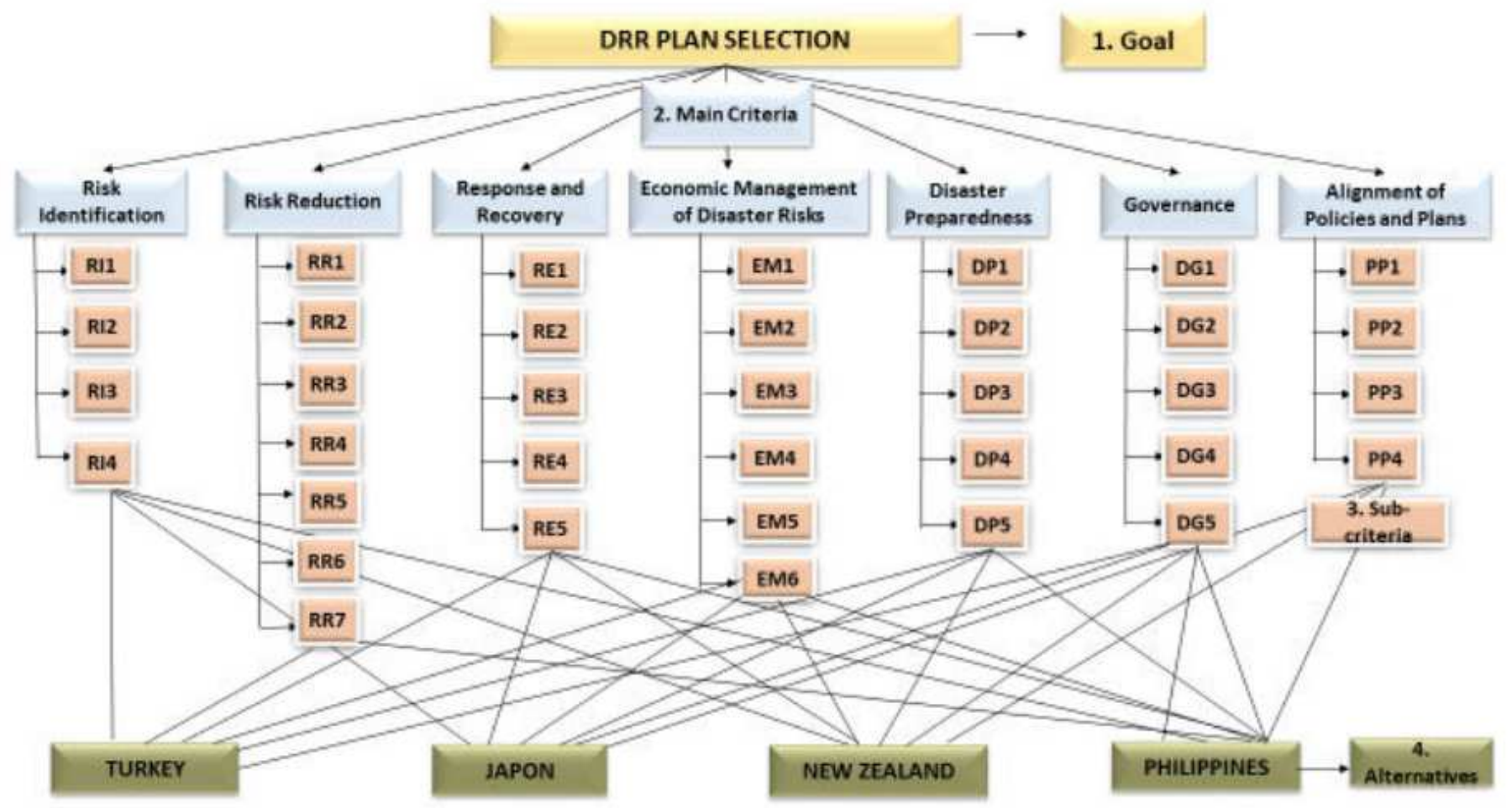

Fig.8

\section{Figure 8}

Third-tier, for each criterion characterizing disaster risk reduction plans represented by represented by 36 important components third tier are determined. Last tier is represented by alternative countries (Fig.8). 


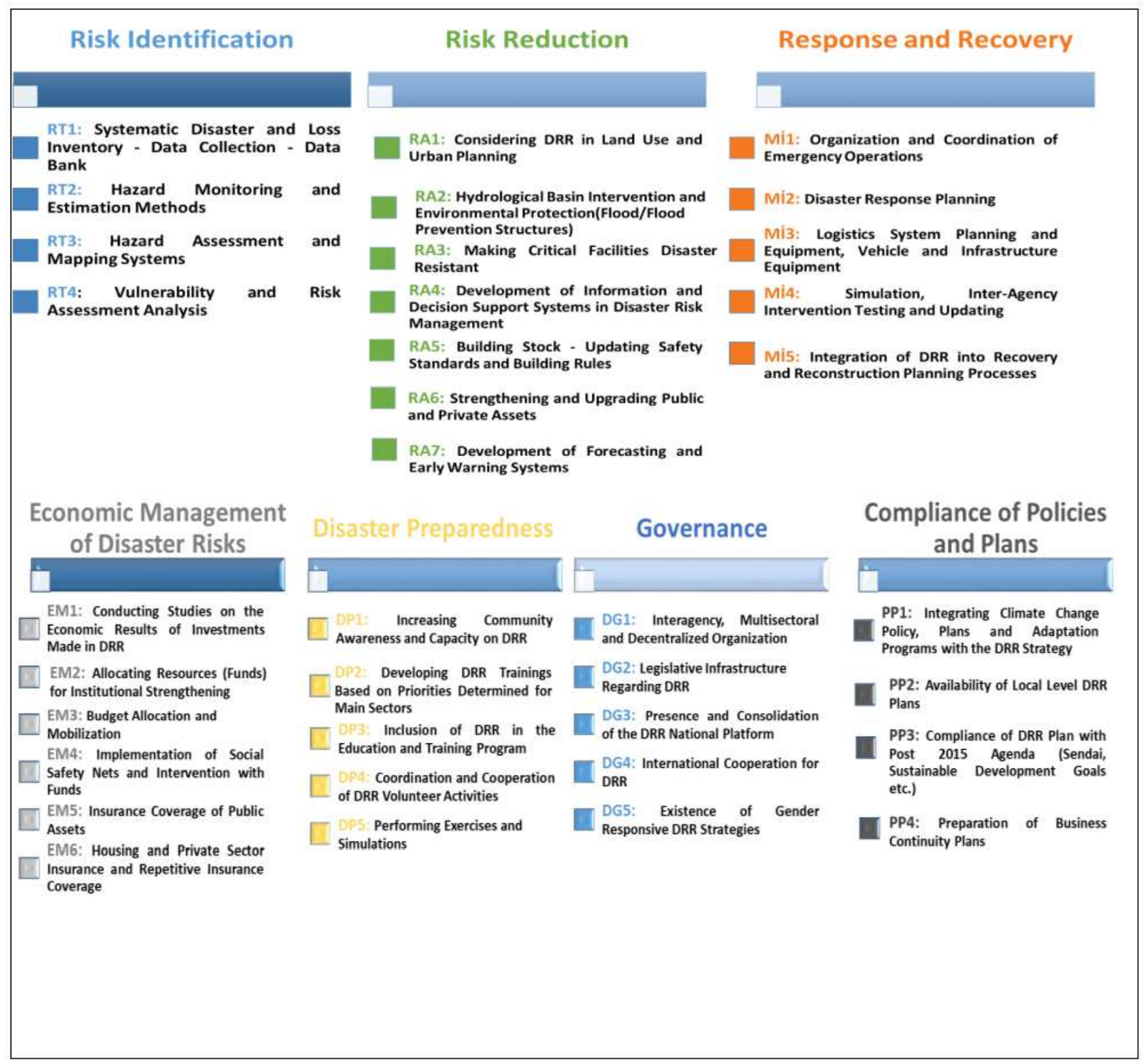

Fig. 9

\section{Figure 9}

The seven main criteria determined are as follows: Risk Identification (B1), Risk Reduction (B2), Response and Recovery (B3), Economic Disaster Risk Management (B4), Disaster Preparedness (B5), Governance (B6) and Compliance of Policies and Plans (B7), were selected as the main criteria. 36 important components of the main criteria, which explain each one in detail and systematically cover the process, were chosen as sub-criteria (Fig.9). 


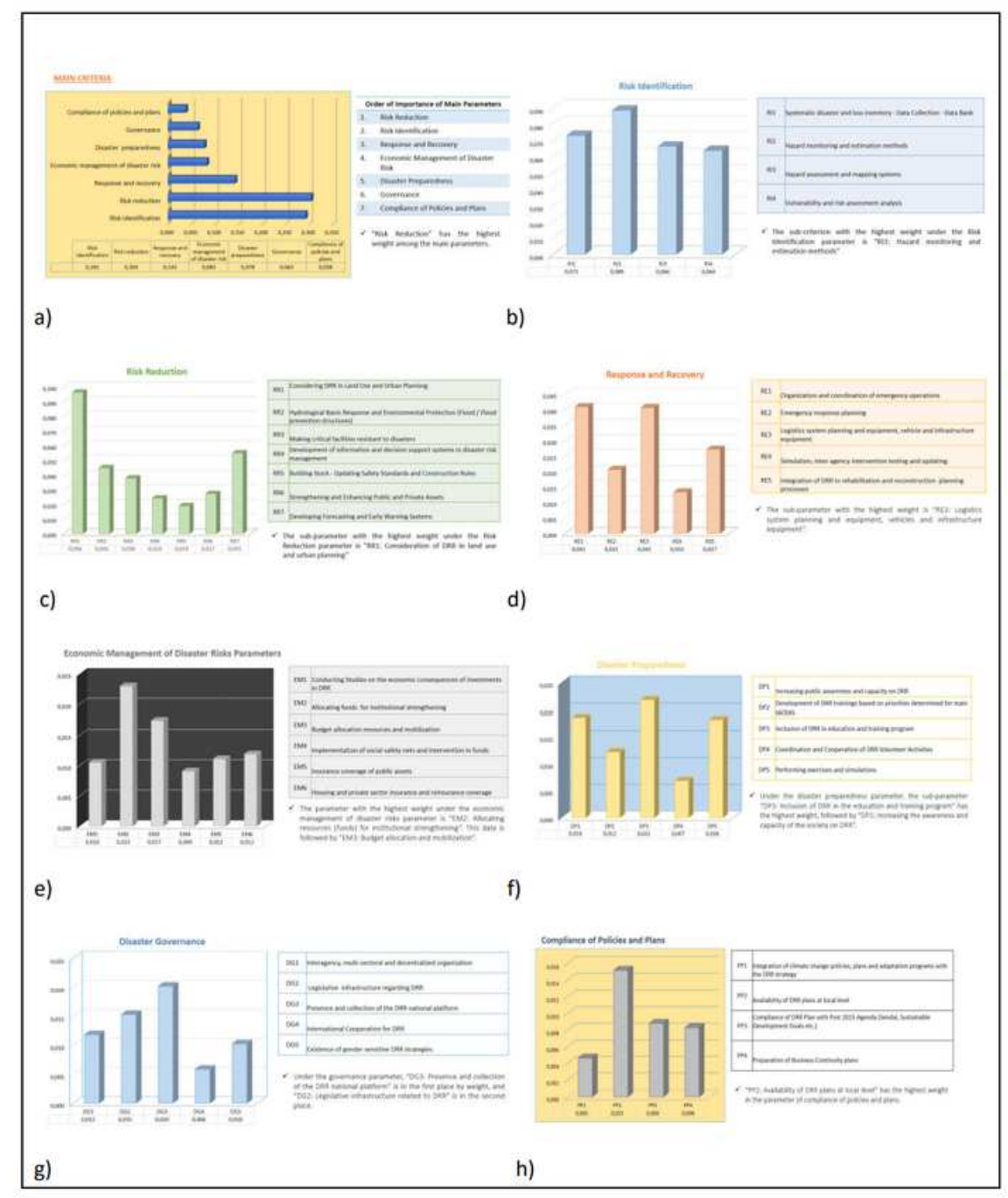

Fig.10

Figure 10

At the lowest level, the countries whose DRR plans are examined are listed as alternatives-hierarchical model (Fig.10). 


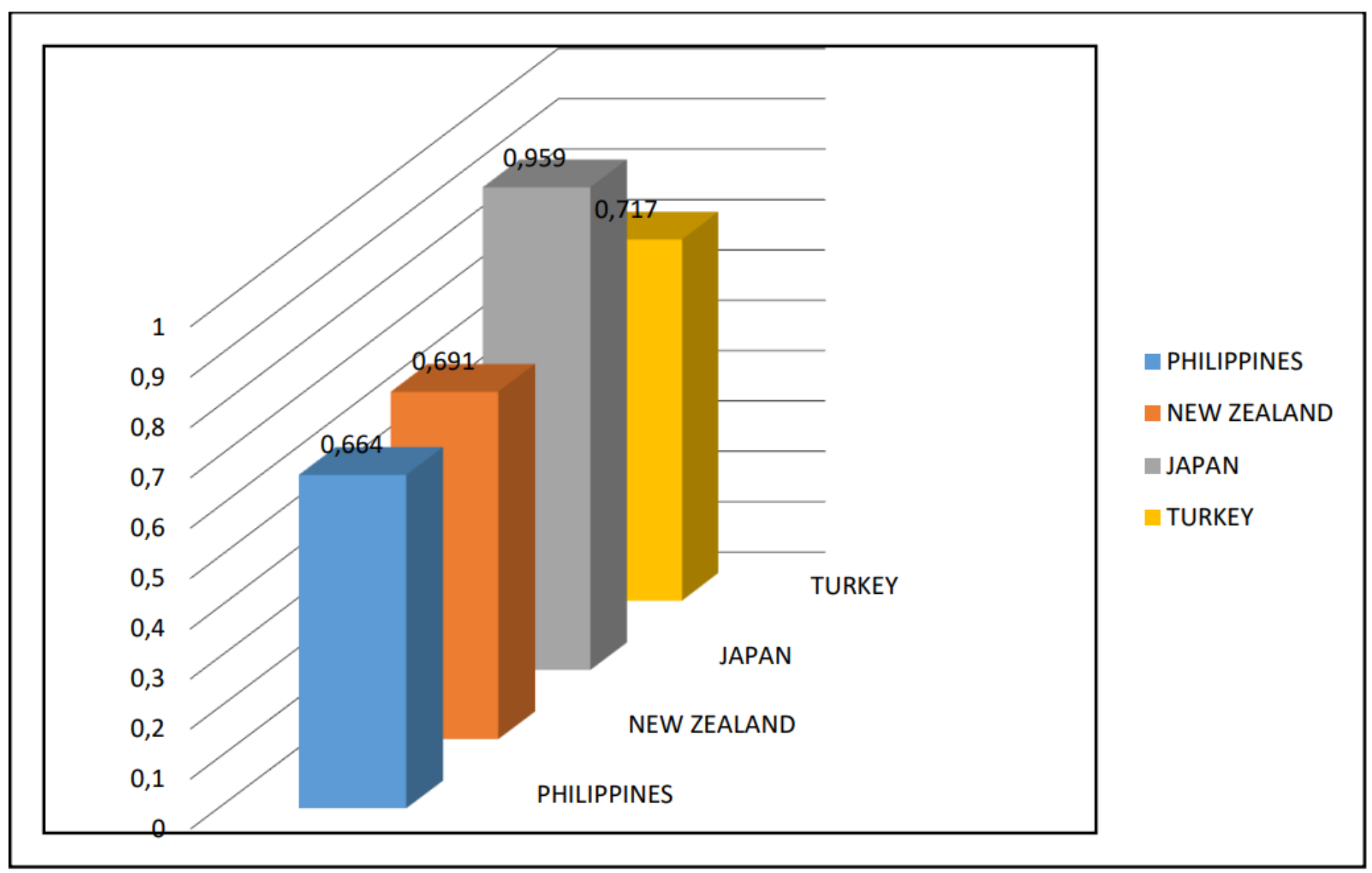

Fig.11

Figure 11

At the end of the analysis, Japan was determined as the country with the best DRR plan and implementation, while our country was ranked 2nd, New Zealand ranked 3rd and Philippines ranked 4th (Fig.11) 